\title{
Development and validation of a questionnaire to assess facilitators and barriers to physical activity for patients with rheumatoid arthritis, axial spondyloarthritis or psoriatic arthritis
}

Thomas DAVERGNE ( $\nabla$ thomas.davergne@gmail.com )

Sorbonne Univerite INSERM https://orcid.org/0000-0001-7869-0062

\section{Rikke H Moe}

Diakonhjemmet Sykehus AS

\section{Bruno Fautrel}

Sorbonne Universite, Pitié-Salpêtrière hospital, rheumatology department

\section{Laure Gossec}

Sorbonne Universite, Pitie-Salpetriere hospotal, Rheumatology department

\section{Research}

Keywords: Barriers and facilitators, Physical activity, Axial Spondyloarthritis, Rheumatoid Arthritis, Psoriatic Arthritis, questionnaire

Posted Date: June 2nd, 2020

DOI: https://doi.org/10.21203/rs.3.rs-32149/v1

License: (9) This work is licensed under a Creative Commons Attribution 4.0 International License. Read Full License

Version of Record: A version of this preprint was published at Rheumatology International on August 30th, 2020. See the published version at https://doi.org/10.1007/s00296-020-04692-4. 


\section{Abstract}

Objectives: The objective was to develop and validate a self-administered questionnaire to identify in people with Inflammatory arthritis (IA) Facilitators And Barriers to Physical activity (PA): the IFAB questionnaire.

Methods: The development of the questionnaire included a systematic review of barriers and facilitators to PA to identify key themes, face validity assessment by 11 experts and cognitive debriefing with 14 patients. The psychometric properties of the questionnaire were assessed by convergent validity (Spearman correlation) against the modified Health Assessment Questionnaire (mHAQ), the FearAvoidance Beliefs Questionnaire subscale for PA and the Tampa Scale for Kinesiophobia, internal consistency (Cronbach a) in 63 IA patients with rheumatoid arthritis (RA), axial spondyloarthritis (axSpA) or psoriatic arthritis (PsA). Reliability and feasibility were assessed in 32 IA patients.

Results: The questionnaire comprises 10 items: 4 assessing either barriers or facilitators, 3 assessing barriers and 3 assessing facilitators. The items are related to: psychological status $(N=6)$, social support $(N=2)$, disease $(N=1)$, environmental factors $(N=1)$. In the validation study of 63 patients: $26 R A, 24$ axSpA, 13 PsA; mean age 52.8 (standard deviation 16.5) years, mean disease duration 12.5 (12.3) years, $53 \%$ women. The questionnaire was correlated $(r=0.24)$ with mHAQ. Internal consistency (Cronbach a 0.69 ) and reliability (interclass coefficient 0.79 [95\% confidence interval $0.59 ; 0.88]$ ) were satisfactory, as was feasibility (missing data $12 \%$, mean completion time $<5$ minutes).

Conclusion: The questionnaire allows the assessment of barriers and facilitators to PA in patients with IA. This questionnaire may guide targeted interventions to increase levels of PA in these patients.

\section{Introduction}

Axial spondyloarthritis (axSpA), rheumatoid arthritis (RA) and psoriatic arthritis (PsA) are the most prevalent inflammatory rheumatic diseases, representing $2 \%$ of the general population $[1,2]$. They share common characteristics such as inflammation, pain and fatigue, systemic manifestations and can potentially lead to structural changes in joint or spine with loss of function $[1,3]$.

According to the World Health Organization (WHO), physical inactivity (lack of physical activity) has been identified as the fourth leading risk factor for global mortality [4]. Patients with these 3 inflammatory arthritis (IA) i.e., RA, SpA or PsA, are more prone to physical inactivity than the general population [5]. For example, only a quarter of axSpA patients met the recommended level of physical activity (PA) [5] and PA objectively measured by a tracker revealed that RA patients performed 200 minutes of PA per week less than healthy subjects [6].

Patients with IA derive specific benefits from regular PA. These include, in particular, reduction of pain intensity and risk of cardiovascular diseases $[7,8]$. For example in AxSpA, increased PA leads to improved 
physical function and reduced fatigue and disease-related activity [9]. Thus, PA is a key component of clinical practice guidelines for the management of these rheumatic conditions $[8,10,11]$.

Increasing PA is a challenge [12]. Lifestyle changes (such as PA levels) should be addressed by a global approach and by taking into account behavioural barriers to increase chances of success [13]. Regarding PA, barriers and facilitators have been identified [14]. Barriers appear to be mostly related to psychological status, and facilitators are linked in part to social support [14,15]. Questionnaires can be used to assess barriers and facilitators, which could be useful in developing interventions tailored to the patient's needs, and thus more likely to be successful. Such a questionnaire could be also valuable in the process of implementing physical activity recommendations [16].

For the general population and for people with osteoarthritis, questionnaires have been developed to assess barriers and facilitators to PA $[14,15]$. However, barriers in IA may be different due to the specific burden of the disease, including pain and fatigue, but also structural damage possibly leading to joint or spine functional impairment [3]. Furthermore, patients with IA may have erroneous beliefs regarding PA [12]. To our knowledge, no questionnaire assessing perceived barriers and facilitators to PA has been validated for patients with IA.

The aim of this work was to elaborate a self-administered questionnaire to identify the perceived barriers and facilitators to PA in people with IA, and to validate the questionnaire in terms of psychometric properties.

\section{Methods}

The study was developed according to COnsensus-based Standards for the selection of health Measurement INstruments (COSMIN) and Outcome Measures in Rheumatology (OMERACT) $[17,18]$.

Several phases were performed, to generate, select and score items for the questionnaire, then to assess the psychometric properties of this questionnaire and to finalise the questionnaire and assess its reliability. These steps are shown in Fig. 1.

\subsection{Phase 1: Systematic review of barriers and facilitators to physical activity}

The first step aimed to inform the choice of barriers and facilitators. Given the more abundant literature in RA, we chose to concentrate the systematic review on barriers and facilitators to PA for RA patients. The search was performed in Medline, Web of Science and the grey literature, as well as bibliography of included studies and related studies, from inception to January 2019. Key search terms were exercise [MeSH], barriers [Title/Abstract], facilitators [Title/Abstract] and Arthritis, Rheumatoid [MeSH]. All qualitative reports of barriers and facilitators in RA, published in English were collected. A thematic synthesis was applied to extract main barriers and facilitators to PA, which were selected when reported at least in 2 publications, then grouped by theme by the experts. 


\subsection{Phase 2: Identification of the questionnaire items}

First, each main barrier and facilitator from the systematic review was formulated using the patients' verbatim where possible. Items were presented at either barriers, facilitators or either one of those categories. This preliminary wording was then assessed for face validity, and reworded where needed, by 11 experts in rheumatology or physiotherapy. Finally, the preliminary questionnaire was tested by 14 patients with IA through cognitive debriefing, and the items were reworded if needed [19]. For this, consecutive outpatients were contacted from one tertiary care hospital in France. They were aged above 18, with definite RA based on the ACR/EULAR classification criteria of rheumatoid arthritis [20], or axSpA based on the Assessment of SpondyloArthritis international Society classification criteria [21] with no restriction for co-morbidities and were able to read and write in French language. At that step, items were developed simultaneously in English and French and the quality of the cross-cultural validity was tested using the usual translation and back-translation procedure (29). The following steps were carried out using the French version.

\subsection{Phase 3: Scoring}

Based on the cognitive debriefing, we chose to first ask for impact of each item on PA (yes/no), then to rate the impact on PA on a numeric scale ranging from 0 (no impact) to 10 (maximal impact). Rating the impact is important since other authors have demonstrated that the presence or absence of an item is not enough to discriminate between active and inactive participants, and that the extent to which the items impact PA should be noted [22]. Items which can be considered as either barriers or facilitators are rated from -10 to 10 , items which are barriers only are rated from -10 to 0 , and items which are facilitators only are rated from 0 to 10 . This scoring has been used previously [22]. When an item was indicated as not affecting physical activity, it was scored at 0 .

\subsection{Phase 4: Evaluation of the psychometric properties and finalisation of the IFAB}

To assess the items and different versions of the Inflammatory arthritis Facilitators And Barriers questionnaire (IFAB), several analyses were performed.

Study design

A prospective cross-sectional and longitudinal monocentre study was conducted in a single tertiary care centre in Paris, France. The longitudinal component concerned a subset of patients for reliability. The validation study was accepted by the ethics committee (CPP Sud-Est III, France, EudraCT 2019-A0141354, methodology MR03 for non-interventional study). Participant informed consent was collected before inclusion.

Population 
All patients who satisfied the inclusion criteria, seen in outpatient visits from November 2019 to January 2020 were asked to participate. The inclusion criteria were: age above 18; definite IA confirmed by the rheumatologist: axSpA (referring to the Assessment of SpondyloArthritis international Society classification criteria [21]), RA (referring to the international classification criteria of RA [20]) or PsA (referring to the CIASsification of Psoriatic ARthritis (CASPAR) criteria [23]); agreement to participate and informed consent; ability to read and write in the language of participating country. There were no restrictions for comorbidities; however, bed-ridden patients were excluded.

\section{Instruments administered}

The participants completed self-administered questionnaires: the newly-developed IFAB questionnaire, the Modified Health Assessment Questionnaire (mHAQ) to assess functional status [24], the FearAvoidance Beliefs Questionnaire subscale for PA (FABQ-PA) to assess patients' fear avoidance and beliefs about PA [25], the Tampa Scale for Kinesiophobia (TSK) to assess the subjective rating of kinesiophobia or fear of movement [26] and the Bath Ankylosing Spondylitis Disease Activity Index (BASDAI) to assess disease activity for patients with AxSpA [27] (online supplementary Table 1). In RA, disease activity was assessed by the physician through the Disease Activity Score 28 (DAS28) [28]. Disease duration, level of pain and patient global assessment were also collated. Finally, the steering committee developed two numeric rating scale global questions related to PA as follows: "when I think about the PA I want to do, I feel held back and limited" and "when I think about the PA I want to do, I feel supported and encouraged"

Reliability was explored by test-retest one week after the first completion. The second completion concerned only the IFAB, and was filled in from home.

All questionnaires were administered in French, using the French versions.

\section{Analysis of psychometric properties and choice of the final IFAB items}

Based on the validation study, the steering committee finalized the questionnaire: the objective was to aim for brevity (to enhance feasibility) without losing content validity, leading to possible deletion of some questions. The selection of the most relevant items for the final IFAB was based on correlation against legacy measures, correlation between each item and the total score (Spearman's Rho coefficient greater than 0.5 , with $P<0.05$ ), clinical relevance (modifiable items were preferred), and reliability of each item (intraclass correlation coefficient, ICC $>0.5$ ). Construct validity of each item and of several versions of the IFAB questionnaire were assessed against each of the legacy questionnaires. The hypotheses included: for convergent validity, correlation between the IFAB and the individual items and the legacy questionnaires assessing related concepts (mHAQ, FABQ-PA, TSK); and for divergent validity, absence of correlation with BASDAI, DAS28, level of pain, patient global assessment and disease duration. A correlation between the IFAB and the two simple questions related to PA was also expected. Reliability was assessed on the sub-set of patients with stable symptoms since the first completion. 
The distribution of the scores was evaluated for the questionnaire score and items by the mean, standard deviation, range and median. Floor and ceiling effects were investigated for the questionnaire score and items (accepted maximum for both: 15\%). Internal consistency and feasibility were also analysed. Respondent acceptability was considered satisfactory for a frequency of missing data $<15 \%$ on the retest. Feasibility was also tested by measuring the duration of completion on 10 participants.

\subsection{Statistical analyses}

For assessment of psychometric properties, a sample size of 60 patients was aimed for validity, and 30 patients for reliability, as proposed by COSMIN, without a formal calculation of power [18]. Statistical analyses were performed using $\mathrm{R}$ version 3.5.1. Continuous data were presented as mean (standard deviation (SD)). There was no imputation of missing data. Convergent and divergent validity were assessed by Spearman's correlations, considered very small if $<0.30$, small if 0.30 to 0.50 , moderate if 0.50 to 0.70 and strong if $>0.70$ [29]. ICC was based on the two-way random effect model, and coefficients $>0.70$ were considered satisfactory. Internal consistency of the questionnaire was determined by Cronbach's a, and $\geq 0.70$ was considered as satisfactory [30].

\section{Results}

\subsection{Systematic review of barriers and facilitators to physical activity}

Of 89 references, 10 (11.2\%) studies were qualitative reports in RA and were analysed: 3 (49 patients) were focus groups and 7 (99 patients) were individual interviews (Online supplementary Table 2). In all, 148 patients participated: weighted mean age 57.9 years (standard deviation, SD 3.6, range of means 50.0-63.5 years), weighted mean disease duration 13.5 years (SD 5.7, range 6.9-21.0). Barriers and facilitators to PA were reported for general PA in 6 studies and for supervised exercises (e.g. exercise program led by physiotherapist) in 4 studies. Overall, 7 categories of barriers (mean 3.4 (SD 1.9) per study) and 8 categories of facilitators (mean 3.7 (SD 2.1) per study) were reported (Table 1). These could be grouped in 4 major themes psychological status, social support, disease, or environmental factors. The 3 most reported categories of barriers were symptoms of RA ( $8 / 10$ studies), beliefs, fears and loss of motivation (7/10) and lack of support, exercise knowledge, confidence and conflict in advice from healthcare (4/10). The 3 most reported categories of facilitators were group socialization and social support (8/10), positive beliefs, knowledge about benefits of PA (5/10) and positive emotions and experiences of PA (5/10). 
Table 1

Systematic review of barriers and facilitators to physical activity in patients with RA

\begin{tabular}{|c|c|c|c|c|}
\hline Major themes & Barriers & $\begin{array}{l}\mathbf{N} \\
\text { studies* }\end{array}$ & Facilitators & $\begin{array}{l}\mathbf{N} \\
\text { studies* }\end{array}$ \\
\hline Disease & Symptoms of RA & 8 & $\begin{array}{l}\text { Stable symptoms } \\
\text { and effective } \\
\text { medication }\end{array}$ & 3 \\
\hline \multirow[t]{2}{*}{$\begin{array}{l}\text { Psychological } \\
\text { status }\end{array}$} & $\begin{array}{l}\text { Negative beliefs and fears (fear of } \\
\text { increase of symptoms), loss of } \\
\text { motivation }\end{array}$ & 7 & $\begin{array}{l}\text { Positive beliefs, } \\
\text { knowledge about } \\
\text { benefits of PA }\end{array}$ & 5 \\
\hline & & & $\begin{array}{l}\text { Positive emotions } \\
\text { and experiences } \\
\text { of PA }\end{array}$ & 5 \\
\hline \multirow[t]{3}{*}{$\begin{array}{l}\text { Environmental } \\
\text { context }\end{array}$} & Bad weather & 3 & $\begin{array}{l}\text { Heat, warm } \\
\text { climate, exercise } \\
\text { in warm water }\end{array}$ & 2 \\
\hline & Inaccessible facilities & 2 & $\begin{array}{l}\text { Convenient } \\
\text { setting: } \\
\text { community or } \\
\text { gym setting, } \\
\text { outside hospital }\end{array}$ & 4 \\
\hline & Lack of time & 2 & & \\
\hline \multirow[t]{3}{*}{ Social support } & Fear of contact with others & 3 & $\begin{array}{l}\text { External } \\
\text { monitoring, } \\
\text { adherence } \\
\text { support (e.g., } \\
\text { reminders) }\end{array}$ & 3 \\
\hline & $\begin{array}{l}\text { Lack of support or exercise knowledge } \\
\text { from healthcare providers, or conflict } \\
\text { in advice from healthcare providers }\end{array}$ & 4 & $\begin{array}{l}\text { Group } \\
\text { socialization, } \\
\text { social support }\end{array}$ & 8 \\
\hline & & & $\begin{array}{l}\text { Support from } \\
\text { healthcare } \\
\text { providers (advice, } \\
\text { empathy) }\end{array}$ & 3 \\
\hline
\end{tabular}

\subsection{Identification of the questionnaire items}

The main themes were reworded into short items and face validity was confirmed by the expert committee. Cognitive debriefing with 14 IA patients led to slight rewordings. The preliminary IFAB contained 14 items: 6 considered as either barriers or facilitators, 4 items as barriers only and 4 items as facilitators only (online Supplementary Table 3).

\subsection{Psychometric properties of the questionnaire}


The study included 63 patients (26 (41\%) RA, 24 (38\%) axSpA, 13 (21\%) PsA), mean age 52.8 (SD 16.5) years, mean disease duration 12.5 (SD 12.3) years, 53\% women (Table 2 and online Supplementary Fig. 1). Disease activity was moderate (mean DAS28 3.8 (SD 1.1), mean BASDAI 3.1 (SD 1.4)) and 73\% received a biological treatment (Table 2).

Table 2

Characteristics of 63 patients with inflammatory arthritis participating in the validation of the IFAB questionnaire

\begin{tabular}{|ll|}
\hline Characteristic & Value \\
\hline Age, years, mean (SD) & $52.9(16.5)$ \\
\hline Inflammatory arthritis & $26(41)$ \\
- Rheumatoid arthritis, N (\%) & $24(38)$ \\
• Psoriatic arthritis, N (\%) & $13(21)$ \\
\hline Gender, female, N (\%) & \\
\hline Disease duration, years, mean (SD) & $33(53)$ \\
\hline Pain intensity: VAS (0-10), mean (SD) & $12.5(12.2)$ \\
\hline Patient global assessment: VAS (0-10), mean (SD) & $3.9(2.7)$ \\
\hline mHAQ (0-3), mean (SD) & $4.0(2.2)$ \\
\hline Kinesiophobia: TSK (17-68), mean (SD) & $0.42(0.46)$ \\
\hline FABQ-PA (0-24), mean (SD) & $44.5(8.1)$ \\
\hline $\begin{array}{l}\text { SD: standard deviation, VAS: visual analogue scale, mHAQ: modified health assessment } \\
\text { questionnaire, TSK: Tampa scale of kinesiophobia, FABQ-PA: fear-avoidance beliefs questionnaire for } \\
\text { physical activity. }\end{array}$ & $9.0(6.2)$ \\
\hline
\end{tabular}

Final version of the questionnaire

Based on the results and the pre-defined criteria, the decision was taken to reduce the questionnaire from 14 items to 10 items (Table 3 and (online Supplementary Table 3). In the final questionnaire, 4 items can be considered either as barriers or facilitators, 3 items as barriers only and 3 items as facilitators only (Tables 3 and 4). The score of the final list of items can vary between -70 and 70 (Fig. 1). The items are related to: psychological status $(N=6)$, social support $(N=2)$, disease $(N=1)$, or environmental factors $(N$ =1) (Table 3). 
Table 3

The 10 items of the IFAB questionnaire to assess barriers and facilitators to physical activity

\section{Barriers or facilitators*}

1. Level of symptoms (pain, fatigue, lack of mobility)

2. Weather conditions

3. Presence or absence of support from others (friends, family)

4. Presence or absence of support and/or advice from healthcare professionals
Facilitators

5. A belief that physical activity will make symptoms worse

6. Lack of motivation

7. Lack of knowledge on which exercises to do and how much
Barriers

8. Knowledge of benefits of physical activity for health

9. Knowledge of benefits of physical activity for mood

10. Confidence on how to exercise safely

*These items can be either a barrier or a facilitator.

Items which can be considered as either barriers or facilitators are rated from - 10 to 10 , items which are barriers only are rated from - 10 to 0 , and items which are facilitators only are rated from 0 to 10 . The score of the final questionnaire can vary between -70 and 70 . 
Table 4

Performance of the IFAB items and final IFAB questionnaire

\begin{tabular}{|c|c|c|c|c|c|c|}
\hline $\begin{array}{l}\text { Item or final } \\
\text { IFAB (range } \\
\text { of possible } \\
\text { values) }\end{array}$ & $\begin{array}{l}\text { Score, } \\
\text { mean } \\
\text { (SD) } \\
\text { [median] }\end{array}$ & $\begin{array}{l}\text { Range } \\
\text { (min;max) }\end{array}$ & $\begin{array}{l}\text { Missing } \\
\text { values } \\
\text { at retest } \\
(\%)^{\star}\end{array}$ & $\begin{array}{l}\text { Floor/ceiling } \\
\text { effect (\%) }\end{array}$ & $\begin{array}{l}\text { Intraclass } \\
\text { Correlation } \\
\text { coefficient }(95 \% \\
\text { confidence } \\
\text { interval) ** }\end{array}$ & $\begin{array}{l}\text { Correlation } \\
\text { with IFAB: } \\
\mathrm{R} \text { (p value) }\end{array}$ \\
\hline $\begin{array}{l}\text { Item } 1 \\
(-10 ; 10)\end{array}$ & $\begin{array}{l}-3.2(3.9) \\
{[-4]}\end{array}$ & $(-10 ; 7)$ & 0 & $2 / 0$ & $0.65(0.42 ; 0.81)$ & $0.43(0.01)$ \\
\hline $\begin{array}{l}\text { Item 2 } \\
(-10 ; 10)\end{array}$ & $\begin{array}{l}-2.7(3.7) \\
{[0]}\end{array}$ & $(-10 ; 7)$ & 0 & $2 / 0$ & $0.49(0.18 ; 0.72)$ & $\begin{array}{l}0.33(< \\
0.001)\end{array}$ \\
\hline $\begin{array}{l}\text { Item } 3 \\
(-10 ; 10)\end{array}$ & $\begin{array}{l}0.0(5.1) \\
{[0]}\end{array}$ & $(-10 ; 10)$ & 3 & $2 / 8$ & $0.60(0.33 ; 0.79)$ & $\begin{array}{l}0.57(< \\
0.001)\end{array}$ \\
\hline $\begin{array}{l}\text { Item } 4 \\
(-10 ; 10)\end{array}$ & $\begin{array}{l}1.9(4.2) \\
{[0]}\end{array}$ & $(-6 ; 10)$ & 3 & $0 / 7$ & $0.34(0.03 ; 0.62)$ & $\begin{array}{l}0.56(< \\
0.001)\end{array}$ \\
\hline Item $5(-10 ; 0)$ & $\begin{array}{l}2.3(3.7) \\
{[0]}\end{array}$ & $(-10 ; 0)$ & 0 & $2 / 73$ & $\begin{array}{l}0.01 \\
(-0.33 ; 0.35)\end{array}$ & $0.36(0.01)$ \\
\hline Item $6(-10 ; 0)$ & $\begin{array}{l}1.9(4.3) \\
{[-3]}\end{array}$ & $(-10 ; 0)$ & 3 & $7 / 42$ & $0.62(0.36 ; 0.80)$ & $0.37(0.01)$ \\
\hline Item $7(-10 ; 0)$ & $\begin{array}{l}-1.6(2.7) \\
{[0]}\end{array}$ & $(-10 ; 0)$ & 3 & $2 / 71$ & $0.61(0.35 ; 0.79)$ & $0.29(0.04)$ \\
\hline Item $8(0 ; 10)$ & $\begin{array}{l}-3.6(3.7) \\
{[6]}\end{array}$ & $(0 ; 10)$ & 3 & $24 / 9$ & $0.51(0.21 ; 0.73)$ & $\begin{array}{l}0.66(< \\
0.001)\end{array}$ \\
\hline Item $9(0 ; 10)$ & $\begin{array}{l}-2.4(3.2) \\
{[5]}\end{array}$ & $(0 ; 10)$ & 6 & $25 / 15$ & $0.71(0.50 ; 0.86)$ & $\begin{array}{l}0.64(< \\
0.001)\end{array}$ \\
\hline Item $10(0 ; 10)$ & $\begin{array}{l}-1.5(2.7) \\
{[0]}\end{array}$ & $(0 ; 10)$ & 3 & $53 / 6$ & $0.59(0.31 ; 0.78)$ & $\begin{array}{l}0.53(< \\
0.001)\end{array}$ \\
\hline $\begin{array}{l}\text { Global IFAB } \\
\text { score }(-70 ; 70)\end{array}$ & $\begin{array}{l}5.1(3.6) \\
{[3]}\end{array}$ & $(-29 ; 57)$ & 13 & $0 / 0$ & $\begin{array}{l}0.79(0.59 \\
0.88)\end{array}$ & - \\
\hline \multicolumn{7}{|c|}{ The items are detailed in Table 3.} \\
\hline \multicolumn{7}{|c|}{ * Missing data in the questionnaire at retest } \\
\hline \multicolumn{7}{|c|}{$\begin{array}{l}\text { \$Floor and ceiling effects are the \% of patients with a minimal or maximal value for the item, which } \\
\text { reflects the item is assessed as not being a barrier or a facilitator. }\end{array}$} \\
\hline
\end{tabular}

\section{Concurrent validity and internal consistency}

Main psychometric properties are shown in Table 4 and online Supplementary Table 4. Convergent validity was partly satisfied, with correlation between the IFAB total score and the mHAQ $(r=-0.24, p<$ 0.05), but no correlation with TSK and FABQ-PA. Divergent validity was satisfied (online Supplementary Table 4). The questionnaire score had a significant positive correlation with the single questions related to the feeling of support and encouragement $(r=0.32, p<0.05)$ and a significant negative correlation with 
the feeling of limitation $(r=-0.29, p<0.05)$ as expected. The internal consistency of the final version of the questionnaire was good (Cronbach a values $=0.69$ ).

Data completeness and score distribution

The proportion of missing values ranged from 0 to $6 \%$ for items and was $12 \%$ for the final score at retest (Table 3).

For use in practice, the questionnaire is available online Supplementary Table 5 in English, and from the authors in French. We propose that in case of one missing item, that item is replaced by the value 0 ; in case of 2 or more missing items, the questionnaire cannot be scored.

The distribution of items considered as barrier or facilitator only was not normal (Table 4). Floor and ceiling effect were noted when patients were not affected by a barrier (range, 42-73\%) or facilitator (range $24-53 \%$ ). This reflects the fact that not all barriers/facilitators affect all patients, which was expected.

The global score ranges - 70 to 70 : in the validation study, there were no floor/ceiling effects for the global score. No floor or ceiling effect was observed for the global score.

The completion time was $<5$ minutes.

\section{Reliability}

Of the 48 participants who were asked to complete the questionnaires for the test-retest analysis, 32 were analysed (Online Supplementary Fig. 1). The ICC of the IFAB questionnaire was satisfactory (0.78 [95\% confidence interval, 0.59; 0.88]) (Table 4).

\section{Discussion}

In this study, we have developed an easy to use questionnaire to assess barriers and facilitators to PA for patients with IA. The proposed IFAB questionnaire has 10 items, with a score from - 70 to 70 , higher scores indicating higher levels of facilitation and lower levels of barriers. This questionnaire appears to be feasible, reliable and to have satisfactory internal consistency. This questionnaire may guide targeted interventions to increase PA level of patients with IA.

This study has strengths and weaknesses. The generation of themes was based on a systematic literature review of barriers and facilitators to PA for patients; however the review concerned RA only, due to the more extensive literature in this population. Recently, similar barriers and facilitators have been evidenced in patients with AxSpA [12] and to our knowledge barriers and facilitators to PA have not been studied in patients with PsA. Cognitive debriefing was applied to improve the understandability of items by patients. Cognitive debriefing is an important step and generally under-used [19]. The development process of the questionnaire involved a variety of experts, including physiotherapists, which is rarely the 
case. The assessment of psychometric properties was complete, including internal consistency, construct validity, data completeness and reliability [18]. Many questionnaires applied in rheumatology have not undertaken such a complete psychometric assessment [18]. The sample size of patients to assess the validity of the questionnaire $(n=63)$ was low but is considered by COSMIN as adequate [18]. The sample size for reliability may be considered as low $(n=32)$ [18]. However, proper statistical analysis was used (ICC) and reliability was satisfactory [18]. No analysis of differential effect in different diseases was carried out. However, all the 3 IA diseases were represented and levels of pain and functional status were equivalent among IA diseases (data not shown). The absence of correlation between the IFAB and questionnaires assessing fear avoidance/beliefs about PA and kinesiophobia was unexpected. However, the IFAB questionnaire assesses several dimensions and some of these are not related to fears (avoidance or kinesiophobia), such as social support or level of symptoms. We believe the global nature of the IFAB could explain the lack of correlations. Furthermore, construct validity showed some correlation with functional status, which was expected and strengthens the face validity of the IFAB questionnaire.

Other questionnaires have been developed to assess barriers to PA in the general population [14] or other disabled populations such as osteoarthritis [15], mobility impairments [31], stroke population [32] or coronary artery disease [33]. In these questionnaires, the number of items used to assess barriers varied from 11 to 63. Only one recently-published questionnaire (the EPPA questionnaire) assessed facilitators of PA [15]. Seven out of ten barriers and facilitators of the EPPA questionnaire were also assessed in the IFAB questionnaire, indicating an expected overlap. However, the EPPA questionnaire is applicable to osteoarthritis, not IA. When comparing with a theoretical framework of behaviour change developed by Canes in 2012, we observed that the IFAB questionnaire covers 7 out of the 14 possible domains (knowledge, beliefs about the capabilities, beliefs about consequences, reinforcement, intentions, environmental factors and resources and social influence) [34]. This shows the potential interest of the IFAB questionnaire to examine different aspects of the areas of behaviour change.

PA is highly recommended for the IA population, but not performed sufficiently [6]. There's been a growing interest patient reported outcomes; the Food and Drug Administration underlines their importance and encourages their use [35]. This study applied recommended methodology for the IFAB questionnaire development and validation. The current questionnaire can be both used for research and clinical practice as it takes less than 5 minutes to complete and has little missing data. This questionnaire has the potential to identify perceptions towards PA in order to address barriers such as mistaken beliefs, and encourage facilitators. It may be useful to implement such a questionnaire during patient education to increase awareness of barriers and facilitators or in clinical trials evaluating PA level to observe the relationship between perceived facilitators and barriers and PA levels. The question remains on how to interpret IFAB scores. In the present study, the median of the score was 3 (range - 70 to 70), with a first quartile value (defining the lower $25 \%$ of the group) at -5 . It might be interesting to propose a targeted intervention to patients with the lower scores, for example negative scores or scores below -5 . 
Cultural environment is important to consider when assessing barriers and facilitators. Different aspects of the IFAB questionnaire, such as social environment and psychological status, can be influenced by culture and habits [36]. The questionnaire was validated only in France. However, the systematic review performed to develop the questionnaire included studies conducted in various countries. Moreover, experts involved for the face validity came from different countries (France, Norway and England). The questionnaire was developed both in English and French following a validated translation and crosscultural adaptation process [37]. The culture of PA can change from country to country and from year to year [38]. Policies and regulations vary across the world. Through national prevention plans, increasing numbers of people are aware of the recommendations to perform PA [5]. The popularity of a sport evolves over the years as shown nowadays by the growing interest in running or fitness. Technology is more and more developed and used to promote and track PA and the image of an athletic body is more and more valued [39]. The physical environment is also being adapted to allow regular PA, e.g. through the installation of biking lanes or recreational programs in parks. In addition, the cost of activities tends to decrease. As a consequence, it is possible that this questionnaire will have to be updated in the future.

In conclusion, this short questionnaire may be useful to assess barriers and facilitators in order to increase PA in IA patients. Further studies should assess the relation between IFAB scores and objective $P A$, and assess the efficacy of interventions to improve PA, based on the IFAB score. This questionnaire could be used to design intervention with bigger chance of success and to help implement physical activity recommendations.

\section{Declarations}

Funding: This work was supported by Eli Lilly France and Sandoz France through unrestricted grants. The funders played no role in the design of the study, data collection and analysis, the decision to publish, or the preparation of the manuscript

Conflicts of interest/Competing interests: Thomas Davergne, Rikke $\mathrm{H}$ Moe, Bruno Fautrel and Laure Gossec declare that they have no conflict of interest.

Ethics approval: All procedures performed in studies involving human participants were in accordance with the ethical standards of the institutional and/or national research committee and with the 1964 Helsinki Declaration and its later amendments or comparable ethical standards. The validation study was accepted by the ethics committee (CPP Sud-Est III, France, EudraCT 2019-A01413-54, methodology MR03 for non-interventional study).

Consent to participate: Informed consent was obtained from all individual participants included in the study.

Consent for publication: 'Not applicable' for that section. 
Availability of data and material: The datasets generated during and/or analysed during the current study are available from the corresponding author on reasonable request.

Code availability: : The codes use in R software during the current study are available from the corresponding author on reasonable request.

Authors' contributions: All authors contributed to the study conception and design. Material preparation, data collection and analysis were performed by Thomas Davergne and Laure Gossec. The first draft of the manuscript was written by Thomas Davergne and Laure Gossec and all authors commented on previous versions of the manuscript. All authors read and approved the final manuscript.

Acknowledgements. We thank the expert committee: Laure Combourieu, Maude Barreau, Simone Birnbaum, Noémie Duclos, Timothee Gillot, Matthieu Guemann, Anne Lambert.

\section{References}

1. Feld J, Chandran V, Haroon N, Inman R, Gladman D. Axial disease in psoriatic arthritis and ankylosing spondylitis: a critical comparison. Nat Rev Rheumatol. 2018;14:363.

2. Schett G, Gravallese E. Bone erosion in rheumatoid arthritis: mechanisms, diagnosis and treatment. Nat Rev Rheumatol. 2012;8:656-64.

3. Gossec L, Berenbaum F, Chauvin P, Lamiraud K, Russo-Marie F, Joubert J-M, et al. Reporting of patient-perceived impact of rheumatoid arthritis and axial spondyloarthritis over 10 years: a systematic literature review. Rheumatology Oxford Academic. 2014;53:1274-81.

4. WHO. Global health risks: Mortality and burden of disease attributable to selected major risks. 2009 [cited 2017 Nov 28]; Available from:

http://www.who.int/healthinfo/global_burden_disease/GlobalHealthRisks_report_full.pdf.

5. O'Dwyer T, Rafferty T, O'Shea F, Gissane C, Wilson F. Physical activity guidelines: is the message getting through to adults with rheumatic conditions? Rheumatol U K. 2014;53:1812-7.

6. Barker J, Smith Byrne K, Doherty A, Foster C, Rahimi K, Ramakrishnan R, et al. Physical activity of UK adults with chronic disease: cross-sectional analysis of accelerometer-measured physical activity in 96706 UK Biobank participants. Int J Epidemiol. 2019.

7. Geenen R, Overman CL, Christensen R, Åsenlöf P, Capela S, Huisinga KL, et al. EULAR recommendations for the health professional's approach to pain management in inflammatory arthritis and osteoarthritis. Ann Rheum Dis. 2018;annrheumdis-2017-212662.

8. Peters MJL, Symmons DPM, McCarey D, Dijkmans B, a. C, Nicola P, Kvien TK, et al. EULAR evidencebased recommendations for cardiovascular risk management in patients with rheumatoid arthritis and other forms of inflammatory arthritis. Ann Rheum Dis. 2010;69:325-31.

9. 10.1002/14651858.CD011321.pub2/full

Regnaux J-P, Davergne T, Palazzo C, Roren A, Rannou F, Boutron I, et al. Exercise programmes for ankylosing spondylitis. Cochrane Database Syst Rev [Internet]. 2019 [cited 2019 Nov 17]; Available 
from: https://www.cochranelibrary.com/cdsr/doi/10.1002/14651858.CD011321.pub2/full.

10. Heijde D van der, Ramiro S, Landewé R, Baraliakos X, Bosch FV den, Sepriano A, et al. 2016 update of the ASAS-EULAR management recommendations for axial spondyloarthritis. Ann Rheum Dis. 2017;76:978-91.

11. Wendling D, Lukas C, Prati C, Claudepierre P, Gossec L, Goupille P, et al. 2018 update of French Society for Rheumatology (SFR) recommendations about the everyday management of patients with spondyloarthritis. Joint Bone Spine. 2018;85:275-84.

12. http://doi.wiley.com/10.1002/acr.23705

Niedermann K, Nast I, Ciurea A, Vliet Vlieland T, van Bodegom-Vos L. Barriers and facilitators of vigorous cardiorespiratory training in axial Spondyloarthritis: Surveys among patients, physiotherapists, rheumatologists. Arthritis Care Res [Internet]. 2018 [cited 2019 Jan 9]; Available from: http://doi.wiley.com/10.1002/acr.23705.

13. Knittle K, De Gucht V, Hurkmans E, Peeters A, Ronday K, Maes S, et al. Targeting motivation and selfregulation to increase physical activity among patients with rheumatoid arthritis: a randomised controlled trial. Clin Rheumatol. 2015;34:231-8.

14. Sechrist KR, Walker SN, Pender NJ. Development and psychometric evaluation of the exercise benefits/barriers scale. Res Nurs Health. 1987;10:357-65.

15. Coste N, Guiguet-Auclair C, Gerbaud L, Pereira B, Berland P, Gay C, et al. Perceived barriers to and facilitators of physical activity in people with knee osteoarthritis: Development of the Evaluation of the Perception of Physical Activity questionnaire. Ann Phys Rehabil Med. 2019.

16. Osthoff A-KR, Niedermann K, Braun J, Adams J, Brodin N, Dagfinrud H, et al. 2018 EULAR recommendations for physical activity in people with inflammatory arthritis and osteoarthritis. Ann Rheum Dis. 2018;77:1251-60.

17. Boers M, Beaton DE, Shea BJ, Maxwell LJ, Bartlett SJ, Bingham CO, et al. OMERACT Filter 2.1: Elaboration of the Conceptual Framework for Outcome Measurement in Health Intervention Studies. J Rheumatol. 2019;jrheum.181096.

18. Mokkink LB, Prinsen CA, Patrick DL, Alonso J, Bouter LM, de Vet HC, et al. COSMIN Study Design checklist for Patient-reported outcome measurement instruments. 2019;32.

19. Hewlett S, Nicklin J, Bode C, Carmona L, Dures E, Engelbrecht M, et al. Translating patient reported outcome measures: methodological issues explored using cognitive interviewing with three rheumatoid arthritis measures in six European languages. Rheumatology. 2016;55:1009-16.

20. Aletaha D, Neogi T, Silman AJ, Funovits J, Felson DT, Bingham CO, et al. 2010 Rheumatoid arthritis classification criteria: An American College of Rheumatology/European League Against Rheumatism collaborative initiative. Arthritis Rheum. 2010;62:2569-81.

21. Rudwaleit M, Heijde D van der, Landewé R, Listing J, Akkoc N, Brandt J, et al. The development of Assessment of SpondyloArthritis international Society classification criteria for axial spondyloarthritis (part II): validation and final selection. Ann Rheum Dis. 2009;68:777-83. 
22. Brittain DR, Gyurcsik NC, McElroy M, Hillard SA. General and Arthritis-Specific Barriers to Moderate Physical Activity in Women With Arthritis. Womens Health Issues. 2011;21:57-63.

23. Taylor W, Gladman D, Helliwell P, Marchesoni A, Mease P, Mielants H. Classification criteria for psoriatic arthritis: Development of new criteria from a large international study. Arthritis Rheum. 2006;54:2665-73.

24. Pincus T, Summey JA, Soraci SA, Wallston KA, Hummon NP. Assessment of patient satisfaction in activities of daily living using a modified Stanford Health Assessment Questionnaire. Arthritis Rheum. 1983;26:1346-53.

25. Waddell G, Newton M, Henderson I, Somerville D, Main CJ. A Fear-Avoidance Beliefs Questionnaire (FABQ) and the role of fear-avoidance beliefs in chronic low back pain and disability. Pain. 1993;52:157-68.

26. Miller RP, Kori SH, Todd DD. The Tampa Scale: a Measure of Kinisophobia. Clin J Pain. 1991;7:51.

27. Garrett S, Jenkinson T, Kennedy LG, Whitelock H, Gaisford P, Calin A. A new approach to defining disease status in ankylosing spondylitis: the Bath Ankylosing Spondylitis Disease Activity Index. J Rheumatol. 1994;21:2286-91.

28. Prevoo ML, van 't Hof MA, Kuper HH, van Leeuwen MA, van de Putte LB, van Riel PL. Modified disease activity scores that include twenty-eight-joint counts. Development and validation in a prospective longitudinal study of patients with rheumatoid arthritis. Arthritis Rheum. 1995;38:44-8.

29. Gandek B, Ware JE. Methods for validating and norming translations of health status questionnaires: the IQOLA Project approach. International Quality of Life Assessment. J Clin Epidemiol. 1998;51:953-9.

30. Cronbach LJ. Coefficient alpha and the internal structure of tests. 1951.

31. Vasudevan V, Rimmer JH, Kviz F. Development of the Barriers to Physical Activity Questionnaire for People with Mobility Impairments. Disabil Health J. 2015;8:547-56.

32. Drigny J, Joussain C, Gremeaux V, Morello R, Van Truc PH, Stapley P, et al. Development and Validation of a Questionnaire to Assess Barriers to Physical Activity After Stroke: The Barriers to Physical Activity After Stroke Scale. Arch Phys Med Rehabil. 2019;100:1672-9.

33. Joussain C, Joubert J, Laroche D, D'Antono B, Juneau M, Gremeaux V. Barriers to physical activity in coronary artery disease patients: Development and validation of a new scale. Ann Phys Rehabil Med. 2017;60:289-98.

34. Cane J, O'Connor D, Michie S. Validation of the theoretical domains framework for use in behaviour change and implementation research. Implement Sci IS. 2012;7:37.

35. Speight J, Barendse SM. FDA guidance on patient reported outcomes. BMJ [Internet]. British Medical Journal Publishing Group; 2010 [cited 2020 Apr 9];340. Available from:

https://www.bmj.com/content/340/bmj.c2921.

36. Jia Y, Fu H, Gao J, Dai J, Zheng P. The roles of health culture and physical environment in workplace health promotion: a two-year prospective intervention study in China. BMC Public Health. 2018;18:457. 
37. Beaton DE, Bombardier C, Guillemin F, Ferraz MB. Guidelines for the Process of Cross-Cultural Adaptation of Self-Report Measures. Spine. 2000;25:3186.

38. Weinberg R, Tenenbaum G, McKenzie A, Jackson S, Anshel M, Grove R, et al. Motivation for youth participation in sport and physical activity: relationships to culture, self-reported activity levels, and gender. Int J Sport Psychol. Rome, Italy: Edizioni Luigi Pozzie; 2000;31:321-46.

39. 10.1002/acr.23752

Davergne T, Pallot A, Dechartres A, Fautrel B, Gossec L. Use of wearable activity trackers to improve physical activity behavior in rheumatic and musculoskeletal diseases: A systematic review and metaanalysis. Arthritis Care Res [Internet]. 2018 [cited 2018 Sep 25];0. Available from: https://onlinelibrary.wiley.com/doi/abs/10.1002/acr.23752.

\section{Figures}




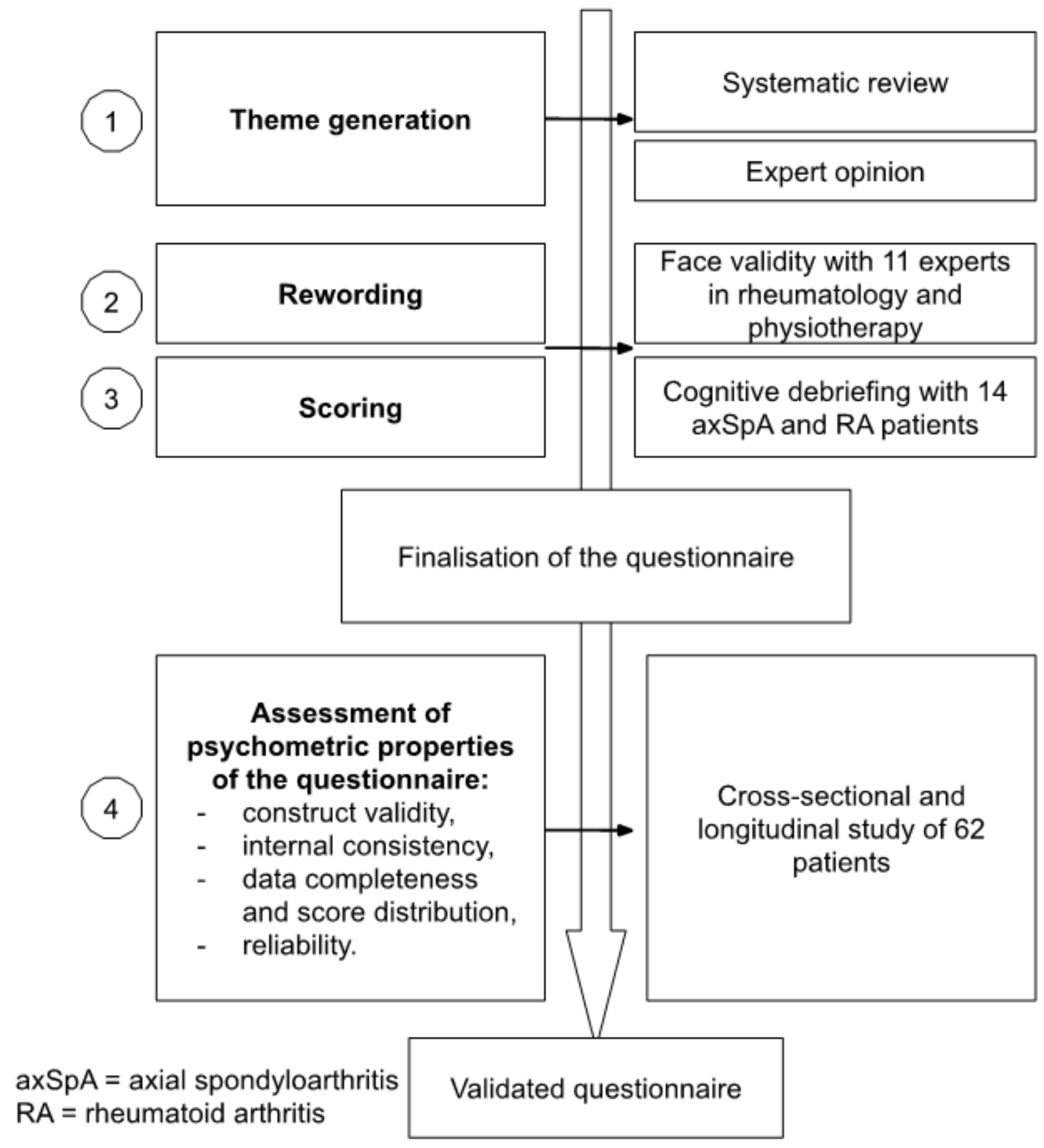

Figure 1

Development and validation of the IFAB questionnaire 
Footnote

$X$ axis: IFAB total score

Y Axis: \% of patients

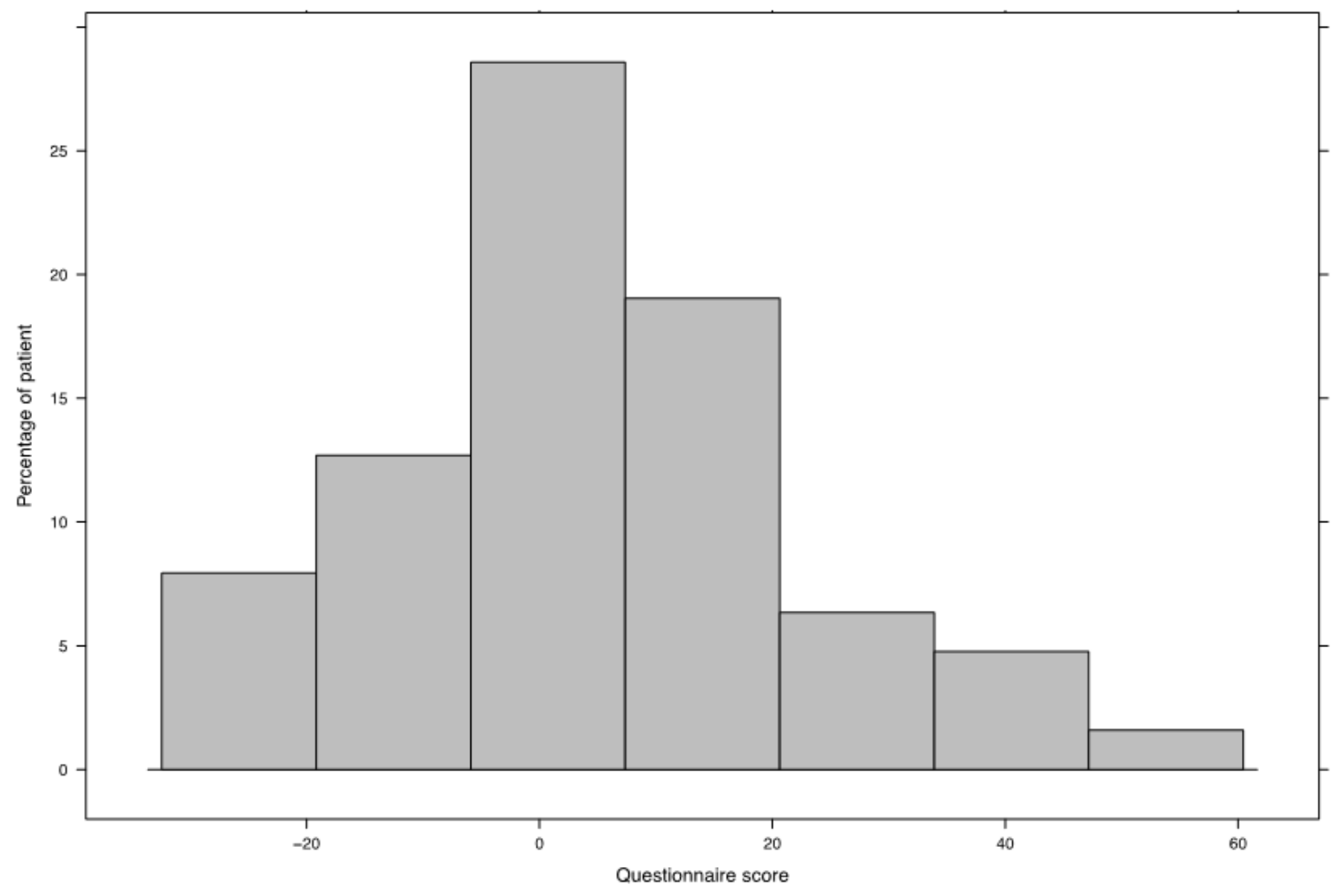

Figure 2

Distribution of the IFAB questionnaire in 63 patients

\section{Supplementary Files}

This is a list of supplementary files associated with this preprint. Click to download.

- Supplementaryonline.pdf 